\title{
Workshops: an important element in medical education
}

\author{
Hiberet Tessema Belay, Brían Ó Ruairc \& Allys Guérandel
}

\begin{abstract}
SUMMARY
Workshops are used in many psychiatric teaching and learning contexts, from undergraduate to continuing professional development. Most psychiatrists have at some time attended a workshop. However, the terms workshop, tutorial and smallgroup teaching are used indiscriminately. It is therefore important to reflect on what characterises a workshop, the learning theories behind their development and what learning needs workshops best meet. We give an outline of the evidence for workshops in medical education and review the principles governing how to conduct workshops and the use of technology to enhance their delivery. Data collected from an undergraduate psychiatry course delivered in an Irish university are used to illustrate how applying these principles contributes to optimising the use of workshops from both the learners' and facilitators' perspective.
\end{abstract}

\section{LEARNING OBJECTIVES}

- Understand what an educational workshop is

- Be able to relate workshops to current approaches in medical education

- Appreciate the use of an effective educational workshop

\section{DECLARATION OF INTEREST}

None.

\section{Keywords}

Education and training; information technologies; workshops; small group teaching.

Medical conferences such as those held by the American Psychiatric Association, the Royal College of Psychiatrists, the College of Psychiatrists of Ireland and many other international medical academic bodies include workshops in their programmes. They are also included in the academic teaching programmes aimed at undergraduates, postgraduates and continuous professional development. Teaching methods such as workshops, which actively require the learner to participate, are widely accepted to achieve a deeper level of learning. However, it is only when workshops are correctly planned and appropriately used that these interactive learning environments foster sound pedagogic principles and result in effective learning. Guidelines for conducting workshops are available and even guidelines specific to psychiatry can be found (Tiberius 2001), but for workshops to be effective it is important to understand the concepts of adult learning, the learning targets and the principles and process of delivering a workshop.

\section{What is a workshop?}

Although both sound pedagogic principles and available evidence support the use of interactive teaching and learning approaches, the format is often variable and the terms small-group teaching, tutorial, seminar, group discussion, problem-based-learning group and workshop are used indiscriminately. In common, such formats imply the engagement of students interacting among themselves and with the teacher, and regardless of the format taken, sessions most often take place in small groups or, if in a large group, the group is divided into smaller subgroups. In tutorials students are set a task, in seminars students research a topic and make a presentation for group discussion of its content (Jaques 2000), and in problem-based learning students follow a specific process to discuss appropriate problems in a group, to increase knowledge and understanding (Wood 2003). In workshops, however, students are encouraged to engage in active experiential learning using planned learning activities focused on the desired learning outcome.

The term workshop has various definitions when applied to learning, and we have chosen one that sits closely to the broadly accepted concept of workshops in education:

\footnotetext{
"A workshop is a short-term learning experience that encourages active, experiential learning and uses a variety of learning activities to meet the needs of diverse learners' (Brooks-Harris 1999: p. 6).
}

\section{How do adults learn?}

Principles from Knowles's work in adult learning inform us that, to be most successful, learning must be interactive; the material presented must be practical, contextual and applicable; and adult learners have a limited attention span of up to 20 min or so. These principles are likely to influence the overall
Hiberet Tessema Belay is a consultant general adult psychiatrist in the Department of Psychiatry, Connolly Hospital Blanchardstown, Dublin, Ireland. Her research interests include medical education. Brían Ó Ruairc is a medical student at the National University of Ireland, Galway, and a graduate in history and political science at Trinity College Dublin. Allys Guérandel is a consultant psychiatrist in the Department of Psychiatry and Mental Health Research, St Vincent's University Hospital, Dublin, and a clinical professor in the School of Medicine and Medical Science, University College Dublin, Ireland. Her research interests include medical education. Correspondence Professor Allys Guérandel, Elm Mount Upper St Vincent's University Hospital, Dublin D04T6F4, Ireland. Email: a.guerandel@st-vincents.ie

\section{Copyright and usage} (C) The Royal College of Psychiatrists 2018 
design of the workshops (Knowles 2012). Workshops therefore should be designed to be varied and broken up into activities lasting up to $20 \mathrm{~min}$ at a time to optimise learning (Bowen 1998).

To utilise experiential learning theories, teaching methodologies that encourage and support learner engagement and foster interaction are required. This involves didactic approaches such as replacing a speaker lecturing to passive learners with discussions, role-play and other such interactive teaching and learning methods.

The evidence for the benefit of interactive teaching and learning styles is found not only in learning theories such as the ones described above but also in research. The literature on medical education informs us that teaching methods that require the learner to participate actively achieve a deeper level of learning. A Cochrane systematic review comparing conferences, lectures, workshops, seminars, symposia and courses on their effectiveness in medical education showed that interactive teaching methods are more effective than didactic lecture-based teaching (Forsetlund 2009). The review also recommends that every effort be made to incorporate interactive learning into standard didactic lessons.

\section{Changes in medical education}

As mentioned, in recent years our evidence-based understanding of adult learning has informed new practices in medical education. This has led to a move towards a learner-centred approach. Alongside these advances in education, the boom in social media and, more importantly, the emergence of the current internet-savvy medical students and trainees have also led to changes in the practices of medical education. Lectures can be podcasted, clips of medical procedures can be viewed on videosharing websites such as YouTube, and virtual patients can be assessed and managed online all at the convenience of the learner.

There is a call for medical educators to incorporate technology and innovation in medical education (Mehta 2013). In problem-based learning an emphasis is given to active learning with constructive facilitation. Similarly, the flipped classroom model urges educators to 'flip' the traditional classroom into an interactive learning environment and advocates the use of online portals to support learning (Tucker 2012). The new paradigm in medical education calls on medical educators to 'just imagine' medical education's renaissance through a massive central collaborative online learning environment and redirecting of valuable faculty time to interactive activities such as workshops for discussion and problem-solving, rather than traditional didactic lectures (Mehta 2013). While embracing technology and incorporating it as a virtual learning support environment, educators urge the use of the 'freed' face-to-face time for more interaction and student engagement (Tucker 2012).

\section{Why choose workshops?}

Workshops with well-defined learning outcomes, utilising principles of experiential learning fit well with current trends in medical education, aligning well with interactive teaching principles. They can be a powerful and effective medium for teaching and potentiating a deeper level of learning. With appropriate pre-planning and design they are a time-efficient way of meeting desired learning outcomes. They are great for brainstorming and building relationships by providing learners with invaluable structured face-to-face contact. They can be delivered in a consistent fashion by different facilitators at a single teaching site or at multi-site teaching centres. They can help remove any ambiguity about individual tutors' approaches to the use of face-to-face time and cater to different facilitation styles. Properly designed, they are a cost-efficient method of producing active involvement of learners compared with individual training activities (Tiberius 2001).

Workshops can be used to deliver teaching for a variety of educational topics and set-ups. They can be used in undergraduate, postgraduate and continuing medical education, as well as at various professional or personal development forums. They are often designed for people working together or in the same field.

What guides one in choosing when to use workshops lies in what one hopes to emphasise for the educational meeting, for example problem-solving, skill-building, increasing knowledge, systemic change or personal awareness/self-improvement (Brooks-Harris 1999). Workshops that problemsolve facilitate systemic change and increased personal awareness/self-improvement; they are therefore favoured in forums providing for continuing medical education or the workplace.

\section{Example of using workshops}

University College Dublin's medical school currently has approximately 250 students in their final year of medical training. The psychiatry module is delivered over 6 weeks four times in the final year for a group of about 60 at a time. Face-to-face teaching time is being reconfigured from didactic lectures to interactive workshops. To date, the following topics are delivered as workshops: psychopathology; the Mental Health Act; eating disorders; psychopharmacology; liaison psychiatry and medically unexplained symptoms; alcohol use and misuse; psychotic disorders; and mood disorders. The 
workshops fit well with the other interactive teaching deliveries used in the module. Outcomes for the workshops are aligned to the overall module learning outcomes and to the assessment methods, which include a continuous clinical assessment, an MCQ paper, a reflective essay and an objective structured clinical examination (OSCE). We will draw from this example to go through the three main stages involved in developing a workshop that we think are essential to achieving an effective teaching and learning experience.

\section{Stage 1 - Pre-planning}

Regardless of the topic or the emphasis of the workshop, adequate pre-planning is mandatory. When designing a workshop, one should be clear as to its objectives and structure learning activities in line with these. It is sometimes necessary to do a needs assessment for learners before deciding on objectives.

In the pre-planning stage consideration should be given to who the participants/learners of the workshop will be, their current level of understanding of the topic and the needs the workshop is aiming to meet. In our workshops this understanding is clearly identified well in advance. Venues and times allocated are also decided well in advance. Access to technologies such as laptops, tablets and projectors is ensured.

Students and tutors have access to the university portal system, Blackboard; this is used extensively throughout module delivery.

It is important to be aware that workshops in medical schools need to be short, generally $1-2 \mathrm{~h}$, as face-to-face teaching time is limited. In our module most workshops are $1 \mathrm{~h}$ long, but for more complex topics such as psychopharmacology modules lasting $2 \mathrm{~h}$ are often required. Remember that the execution of an exercise in a workshop often takes longer than anticipated during pre-planning, therefore it is wise to allow additional time (Tiberius 2001).

In our workshops the ratio of tutor to students is about 1:30, but the students are divided into small groups of 3 or 4 to perform tasks/activities.

Box 1 sums up the key elements of workshop preplanning.

\section{Stage 2 - Planning: workshop structure}

Every workshop should have an introduction, interactive learning activities and a conclusion. It is crucial when planning learning activities that these are matched to set objectives. Care should be taken that the workshop does not drift away from these objectives and remains cohesive as it navigates through the learning activities and comes to a planned conclusion. Although the style of delivery
BOX 1 Key elements of workshop pre-planning

Learning objectives

Clearly define the learning objectives

Time allocation

Fix the duration: usually limited to $1-2 \mathrm{~h}$ in medical schools

Allow enough time for each activity

Each activity should take less than 20 min

Venue

Ensure the room is big enough

Ensure access to the technology needed (e.g. the internet, a projector)

Resources

Facilitator/tutor

Training of the facilitator

Comfort of the facilitator with relevant technology

is often informal and fosters discussion it is important that workshops are well structured.

The introduction should give a concise objective of the workshop and clearly state the expected learning outcomes. A brief outline of the structure of the workshop to follow should then be given. Visual means such as PowerPoint presentations or digital photography can be used creatively to illustrate the introduction.

The crux of the workshop falls in the middle section, where learning activities take place. Designing workshops using Kolb's experiential learning theory, one can choose learning activities to meet the four phases of the learning cycle: concrete experiences, reflective observation, abstract conceptualisation and active experimentation (Kolb 2005).

For the chosen activities to be effective they must be relevant and presentation of the material should be varied and engaging. It is important to encourage learners to relate the workshop content to their reality. Enough time to discuss and reflect on the activities should be built in.

Allowing time to conclude the workshop is also very important. Facilitators usually bring a workshop to an end by allowing time for summing up, drawing conclusions, and reviewing outcomes and feedback.

Getting the plan right is crucial to a successful workshop. The sequence and timing of the activities and discussions must match the allocated time, resources and budget. The more detailed the plan, the more effective the workshop will be.

Box 2 sums up the key elements of workshop planning and structure.

The workshops in the psychiatry module have been designed to emphasise the development of clinical skills and to increase knowledge. In a 
BOX 2 Key elements of workshop planning and structure

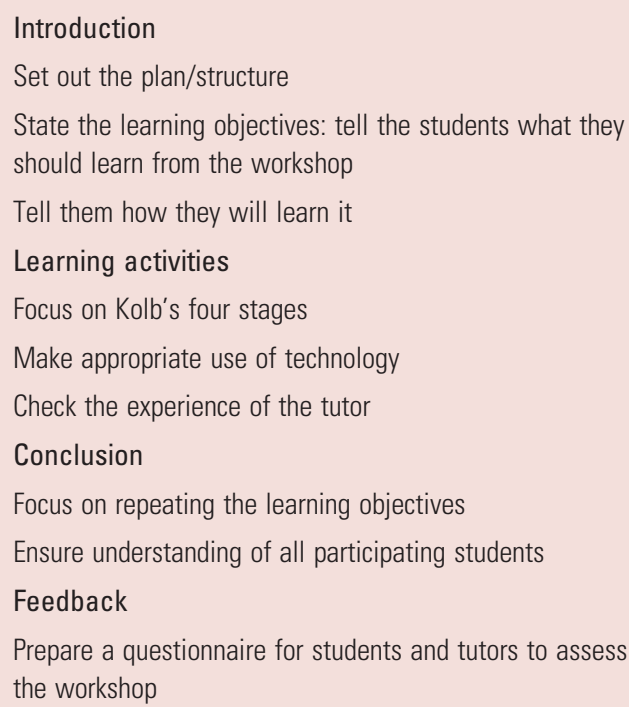

skill-building workshop, content focus is on students practising a specific set of clinical skills, for example eliciting psychotic symptoms or using the Alcohol Use Disorders Identification Test (AUDIT).

Each workshop is carefully planned to have an introduction. Learning activities are listed and timed. Each activity allows time for reflection and there is time at the end of the workshop for summing up. For our module, a manual has been produced detailing the plan, content and activities of all the workshops delivered. This ensures standardisation of delivery across teaching and also facilitates the training of tutors, who change every $1-2$ years.

The next section outlines the content of one of the workshops in the module.

\section{Workshop on alcohol use and misuse}

The content of this workshop, which teaches students about alcohol use and misuse, was developed to follow Kolb's experiential learning theory, with each of its four phases targeted by specific teaching activities.

Reflecting on experience Students are asked to discuss the topic in subgroups and write down harmful consequences of the misuse of alcohol in various areas, as well as completing a quiz.

Assimilating and conceptualization Students' responses are gathered by the facilitator and listed on a flip chart for visual effect. PowerPoint slides on adverse effects of alcohol are shown. A video illustrating harmful use of alcohol is shown for purpose of assimilation and conceptualisation.

These steps allow the learners to reflect and review their knowledge, correcting inconsistencies in their previous understanding of the topic, leading to abstract conceptualisation. The next steps facilitate full understanding.

Experimenting and practising Students are shown a visual image on PowerPoint and are asked to calculate the number of units of alcohol displayed on the slide. They are asked to use the AUDIT tool in pairs and practise screening patients for alcohol misuse.

Planning for application Students are asked to write down what they will do when next seeing a patient with suspected alcohol misuse.

Completion of these four phases is viewed as being significant for effective learning to occur.

\section{Stage 3 - Delivery}

Facilitators are obviously crucial to a workshop. They do not have to be subject experts: it is more important that they are enthusiastic, able to engage learners and start discussions, and have core knowledge of the topic of the workshop. They need to make the group of learners feel comfortable and use humour and ice-breakers appropriately. Facilitators need to bring the learners to the forefront of the learning experience and support them in being active participants in completing their individual cycle of learning. This is a shift in the role of educators from teacher to facilitator (Brook-Harris1999).

There is a vast array of software and interactive platforms that can be used to support the planning and delivery of workshops. They range from Blackboard and Brightspace to Socrative and Mentimeter. As seen in Box 3, videos, quizzes and online forums are just some of the numerous technologies that can be used to support the interactivity of a workshop. With all these options available it is best not to give into techno-centrism, but rather to

B0X 3 Potential workshop learning activities

Video clips
Quizzes
Flip charts
Role-play exercises
Skills practice
Online discussion group
Online whiteboards

Online whiteboards 


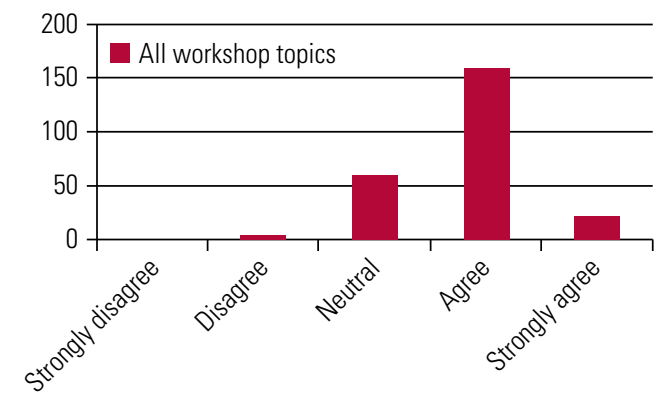

FIG 1

Students' ratings of the relevance of the workshops to the topic covered in the psychiatry module at University College Dublin's medical school.

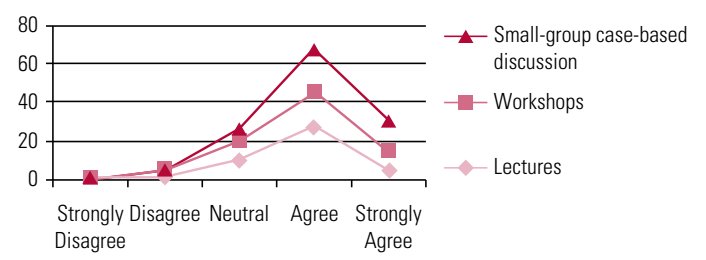

Students' ratings of whether small-group case-based discussion, workshops and lectures were good aids to their learning in the psychiatry module at University College Dublin's medical school.

take into consideration the technological capability of both the learners and the facilitators and then choose the appropriate technology to support the learning tasks.

\section{Stage 4 - Feedback}

Evaluation is the last step. Often, the summing up of the workshop allows for informal discussion on feedback. This is essential to ensure the quality of further delivery of the workshop, but also for the facilitators and their own professional development as educators. Feedback is collected informally by facilitators, and also formally from all stakeholders, including students, facilitators and academic staff, via a questionnaire.
Students taking the psychiatry module were asked to rate the relevance of the workshops to the topic using a five-point Likert scale ( 0 , strongly disagree; 5 , strongly agree). The responses of 246 students are shown in graph form in Fig. 1. It is clear that a majority of the students surveyed either agreed or strongly agreed that the workshops were relevant to the teaching of the topics covered.

The students were also asked to compare and rate lectures, workshops and small-group case-based discussions in terms of how best they aided their learning of various topics. These are the three teaching methods used in set face-to-face time. From the results (Fig. 2) it is clear that students prefer to learn in interactive settings rather than the more traditional lecture settings.

Students were also given an opportunity to write their own individual feedback on the workshops, which also provided some interesting comments (Fig. 3).

Workshop facilitators were also surveyed anonymously for their feedback on the use of workshops (Fig. 4).

All our facilitators had at least a minimum of 6 months' previous teaching experience. Threequarters reported that they had a clear understanding of the differences between workshops and other small-group teaching methods. All our facilitators unanimously responded that they were comfortable using workshops for teaching. They also responded that using workshops as a teaching method made it easier to facilitate learning in the chosen topic and made teaching sessions interactive. They all also felt that learning objectives were appropriately met through the use of workshops. All tutors also reported that it was fun delivering the workshops and that they enjoyed delivering them.

\section{Conclusions}

Most students still expect to be taught in traditional lectures, passively listening while the lecturer speaks on a given subject. However, the feedback

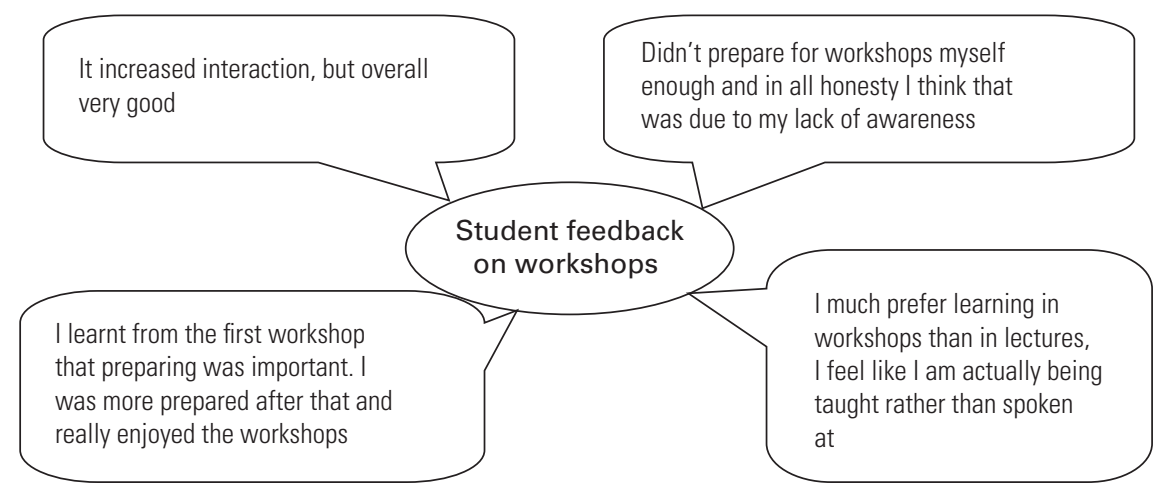

Students' feedback on the workshops of the psychiatry module at University College Dublin's medical school. 


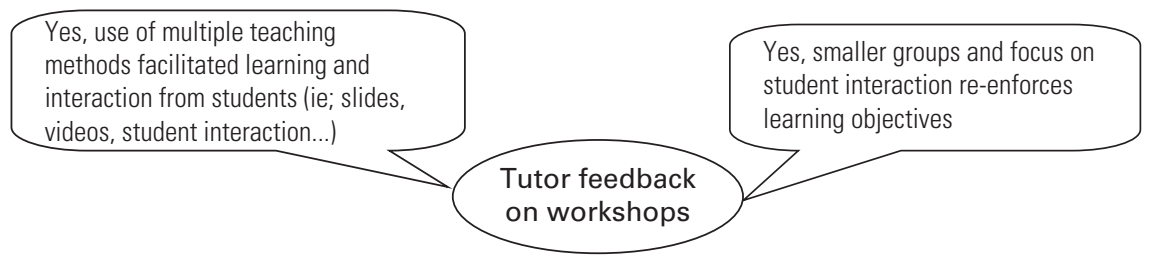

Tutors' feedback on delivering the workshops of the psychiatry module at University College Dublin's medical school.

from some of our students is that they prefer learning in an interactive setting such as a workshop. They are engaged in the learning process and Kolb's theory on experiential learning is more accurately followed.

Although workshops are recognised in medical education as facilitating a deep approach to learning and in our example the students reported a preference for workshops over didactic lectures, workshops are not without their limitations. To be effective they need to be well prepared and the principles and steps discussed here must be followed. Tutors have to be trained to be facilitators. Many are used to delivering didactic lectures and it can take time to normalise using workshops instead.

Finally, not all students take to being taught through workshops: indeed, from the feedback received, our students preferred small-group casebased teaching to workshops. However, what is clear is that most students prefer interactive teaching to traditional didactic lectures and sometimes they just need to be given time to adjust to a new dynamic in the teacher-student relationship. Many students straight out of school struggle initially, having always been taught by teachers sitting at the front of a classroom; graduate entry students adapt more quickly as they have usually come across workshops before.

When participating in a workshop either as a facilitator or as a learner one should anticipate the interactivity and learner-centred approach taken in their delivery. Facilitators have to see their role as enabling learners to engage with the taught material and with each other in a positive way. Equally, learners will maximise the benefit of attending a workshop by preparing appropriately for it and then engaging with the activities and each other.

\section{References}

Bowen JL (1998) Models that Work: The Nuts and Bolts of Faculty Development for General Internal Medicine, Family Medicine and General Paediatrics. Ambulatory Paediatric Association. (http://www. ambpeds.org/education/nutsandbolts/pdfs/modelsthatwork.pdf).

Brooks-Harris JE, Stock-Ward SR (1999) Workshops: Designing and Facilitating Experiential Learning. SAGE Publications.

Forsetlund L, Bjørndal A, Rashidian A, et al (2009) Continuing education meetings and workshops: effects on professional practice and health care outcomes. Cochrane Database of Systematic Reviews, 2: CD003030 (doi: 10.1002/14651858.CD003030.pub2).

Jaques D (2000) Learning in Groups: A Handbook for Improving Group Work (3rd edn). Routledge.

Knowles MS, Holton EF, Swanson RA (2012) The Adult Learner: The Definitive Classic in Adult Education and Human Resource Development (6th edn). Butterworth-Heinemann.

Kolb AY, Kolb D (2005) Learning styles and learning spaces: enhancing experiential learning in higher education. Academy of Management Learning and Education, 4: 193-212.

Mehta NB, Hull AL, Young JB, et al (2013) Just imagine: new paradigms for medical education. Academic Medicine, 88: 1418-23.

Tiberius R, Silver I (2001) Guidelines for Conducting Workshops and Seminars that Actively Engage Participants. Department of Psychiatry, University of Toronto.

Tucker B (2012) The Flipped Classroom Online Instruction at home frees class time for learning. Education Next, 12: 82-3.

Wood DF (2003) Problem based learning. BMJ, 326: 328. 
MCOs

Select the single best option for each question stem

1 Workshops:

a encourage active experiential learning in timeefficient sessions

b are usually run by learners who have researched and present a topic

c use similar activities throughout each one

d are similar to lectures

e are costly to run.

2 Regarding current medical education approaches:

a Kolb's theory propounds that adult learners having an attention span of about $20 \mathrm{~min}$

b evidence based understanding of adult learning has had limited impact on medical education

c both Knowles's and Kolb's learning theories are useful in developing workshops

d online teaching portals are meant to replace faculty members e the use of online portals in medical education is not favoured.

3 The four stages of the experiential learning are:

a concrete experience, reflective experimentation, active observation and abstract conceptualisation

b concrete experience, reflective observation, active conceptualisation and abstract experimentation

c concrete observation, reflective experience, abstract conceptualisation and abstract experimentation

d concrete experience, active observation, reflective conceptualisation and abstract experimentation

e concrete experience, reflective observation, abstract conceptualisation and active experimentation.

4 As regards effective workshops:

a detailed pre-planning and planning of structure are essential b being a subject expert is more important than communication skills in the facilitator

c learning outcomes can be decided after activities are planned

d social media have not been found to be useful in the context of workshops

$\mathrm{e}$ it is best to decide on learning activities during the delivery of the workshop, depending on matters that arise on the day.

5 The use of workshops:

$\mathrm{a}$ is not well supported by the medical education literature

b is not in line with established learning theories

c is in line with trends and calls for renaissance in medical education

d interferes with valuable faculty time

$\mathrm{e}$ is rigorous and time consuming. 